\title{
O sentido religioso e a função política dos agōnes de Olímpia nas épocas arcaica e clássica*
}

Lilian de Angelo Laky**

\begin{abstract}
LAKY, L.A. O sentido religioso e a função política dos agōnes de Olímpia nas épocas arcaica e clássica. R. Museu Arq. Etn., 29: 60-74, 2017.

Resumo: Este artigo apresenta um breve resumo do estado da arte sobre o santuário de Olímpia, tido como centro religioso e político do mundo grego nas épocas arcaica e clássica. Os Jogos Olímpicos são discutidos como parte de um fenômeno religioso, político e de identidade grega próprio desses dois períodos. Nessa perspectiva, é discutido o papel dos Jogos e do culto de Zeus em Olímpia na mobilização das elites das comunidades políticas gregas e na afirmação de identidades políticas, étnicas e regionais.
\end{abstract}

Palavras-chaves Olímpia; Jogos Olímpicos; Identidades; Zeus; Santuários.

\section{Introdução: as origens religiosas e políticas dos Jogos Olímpicos}

\section{A visão tradicional}

Sobre a historiografia acerca das

competições atléticas (os agōnes) praticadas em honra a Zeus no santuário de Olímpia, no sudoeste do Peloponeso, apresentaremos, a respeito de suas origens religiosas e políticas, a visão tradicional (aquela predominante em publicações sobre os Jogos Olímpicos, no Brasil e no exterior) e o debate mais atual (mais difundido nas publicações científicas específicas da área de arqueologia da Grécia).

A visão tradicional sobre a origem dos Jogos Olímpicos (no início da época arcaica) apoia-se

\footnotetext{
* Este artigo oferece um resumo da discussão sobre o santuário de Olímpia e os Jogos Olímpicos nos estudos publicados pela autora nos últimos anos, Laky (2013) e Laky (2016), com o apoio do CNPq e da Fapesp, respectivamente. Todas as traduções de citações diretas contidas neste artigo, à exceção de Sarian (1997), são de minha autoria.

** Mestre e doutora em Arqueologia pelo MAE/USP, pesquisadora do Laboratório de Estudos sobre a Cidade Antiga (Labeca), membro da equipe de escavações em Olímpia do Instituto Arqueológico Alemão de Atenas, desde 2012.<lilian.laky@usp.br>
}

principalmente em várias versões míticas dadas por testemunhos literários bem posteriores, como os de Diodoro Sículo, Pausânias e Estrabão (todos esses autores viveram em época romana). Entretanto, é preciso lembrar que os relatos mais antigos que dispomos sobre a origem dos Jogos Olímpicos estão em Homero e Hesíodo, cujos textos são propriamente contemporâneos à época que a arqueologia tem mostrado como a mais provável para o início das competições atléticas. A menção mais antiga à Olímpia e aos Jogos nos textos antigos aparece na Ilíada (XI, 697-701). Por mais que Homero não tenha mencionado diretamente o santuário, refere-se às corridas de carros realizadas no palácio de Áugias, o rei de Élis (Valavanis 2004: 40). Mas a mais forte e antiga tradição comprovadamente relacionada à fundação dos Jogos Olímpicos é encontrada no Catálogo das mulheres - poema do século VI a.C. tradicionalmente atribuído a Hesíodo, apesar de ser posterior ao poeta. De acordo com a versão no poema, os Jogos foram fundados por Pélope um príncipe da Frígia - que teria derrotado e assassinado o rei Enomau de Élis numa corrida de carros. Pélope casou-se com Hipodâmia, a filha de Enomau, e tornou-se o rei de toda a região, dando o seu nome ao Peloponeso. 
O herói mítico teria fundado os Jogos em agradecimento a Zeus por sua vitória ou, segundo outra versão, em expiação pelo assassinato de Enomau (Valavanis 2004: 41). Já de época clássica, outra versão, fornecida pela primeira vez por Píndaro (Ol. 10.24) no primeiro quartel do século $\mathrm{V}$ a.C., atribui a fundação dos Jogos a Héracles após sua campanha vitoriosa contra Áugias, que recusou a pagá-lo após a limpeza de seus estábulos (Valavanis 2004: 41).

Atualmente, a historiografia reconhece que as duas tradições diferentes que atribuem o início dos Jogos Olímpicos a Pélope e a Héracles, datadas da época arcaica e clássica, foram reapropriadas por autores de períodos mais tardios. A versão sobre Héracles foi retomada por Estrabão (8.3.30; 8.3.33), Pausânias (V, VII. 7-8) e Diodoro (III.74.4; IV.14.1; IV.53.4-5), que acrescentam que o herói foi também o responsável pela escolha do local do santuário e pela dedicação das competições a Zeus Olímpio. Já a versão sobre Pélope aparece somente em Pausânias (V, VIII. 2), que o responsabiliza pela realização dos Jogos em honra ao deus. Uma terceira tradição presente em Estrabão (8.3.33) e Pausânias (V, VIII. 5) associa a instituição dos Jogos a Ífitos, rei de Élis, o qual teria renovado as competições após um grande período de interrupção ${ }^{1}$. Em outro trecho, o periegeta escreve que Ífitos teria criado a trégua sagrada à ocasião das competições e fundado os Jogos a pedido da sacerdotisa do oráculo de Delfos (Pausânias V, IV. 5-6) (Valavanis 2004: 43-44).

Uma das pesquisadoras responsáveis por renovar o conhecimento científico sobre Olímpia, Catherine Morgan defende que as tradições literárias sobre o início dos Jogos Olímpicos refletem os interesses de Élis e dos Estados participantes proeminentes na época arcaica. Estrabão, por exemplo, afirma que os Jogos Olímpicos eram controlados por Élis desde a data

1 De acordo com Yalouris, Óxilos, o líder das tribos etólio-dórias que foram a Élis, é também mencionado como fundador desses novos Jogos, que teriam sido reorganizados por Ífitos, seu descendente. A instituição dos Jogos é igualmente atribuída a Neleu, a Pélias e aos reis de Élis. Todos esses mitos devem ser imputados aos respectivos cultos de diferentes tribos que reinaram em Olímpia em diferentes períodos. Por fim, Pisos, o herói epônimo de Pisa e o principal representante da tradição pisátida rival, é também mencionado como o fundador dos Jogos Olímpicos (Yalouris 2004: 86-87). de sua fundação, e por isso parece se tratar de uma criação política que legitima a administração dos eleios nas competições e no santuário através de supostas práticas ancestrais. Pausânias, por outro lado, parece ter tido mais acesso a tradições locais pré-Élis, as quais sobreviveram no século II d.C., embora seu relato esteja imerso em mitos, lendas e na história de Élis (Morgan 1994: 64). É provável que a versão de Estrabão seja a mais correta, pois hoje sabemos, por meio principalmente de registros epigráficos, que a pólis de Élis, localizada a noroeste de Olímpia, deve ter controlado o santuário e os Jogos ao menos desde o século VI a.C.

À parte dessa documentação que explica a origem dos Jogos Olímpicos pelo viés do mito, dispomos de um segundo tipo de fonte literária antiga que, nesse caso, informa sobre a cronologia dos Jogos. O chamado Catálogo dos vencedores olimpicos assinala o início das competições nos primórdios do século VIII a.C. O texto foi compilado pela primeira vez por Hípias de Élis no século IV a.C. e embora tenha se perdido, os detalhes foram registrados por Aristóteles e, a partir dele, por outros autores antigos (Morgan 1994: 47). Trata-se do texto antigo que consagrou na historiografia sobre a Grécia antiga o ano de 776 a.C. como a data de início dos Jogos Olímpicos. Atualmente, a data ainda aparece em muitas publicações como um divisor de águas na história dos Jogos e na cronologia do mundo grego antigo, mas já se aceita que ela possui pouca relação com outros eventos olímpicos e principalmente com mudanças arqueologicamente detectadas (Morgan 1994: 48; Valavanis 2004: 43). Como veremos mais adiante, atualmente já se aceita, com base nos registros materiais, que as competições em Olímpia se iniciaram posteriormente, ao redor de 700 a.C. (Morgan 1994: 48; Valavanis 2004: 43).

Ainda sobre a historiografia tradicional acerca de Olímpia e os Jogos Olímpicos, muitos estudiosos explicam a origem das competições no santuário por meio do culto agrário e dos jogos fúnebres. Alguns estudiosos preferem explicar a origem dos Jogos Olímpicos com base nos "vários elementos presentes no cronograma das competições associáveis a ritos de fertilidade", portanto ao culto agrário (Sarian 1997: 56). A 
celebração dos Jogos a cada quatro anos com base no mês lunar do calendário grego, a realização do festival no segundo ou terceiro dia da lua cheia depois do solstício de verão, além do uso dos ramos de oliveira selvagem como premiação para coroar os vencedores, sugerem "a assimilação de algum estágio dos Jogos com ritos de fertilidade que celebravam a colheita" e "a cerimônia de premiação seria a reminiscência de algum festival antigo realizado para promover a prosperidade das colheitas, no caso a oliva" (Sarian 1996-1997: 56). Atualmente o culto agrário permanece ainda na historiografia sobre Olímpia como uma das explicações para a origem do culto no santuário, mas os autores preferem relacioná-lo, especificamente, à fase mais antiga do culto de Zeus no local e não genericamente à colheita de olivas. Sobre os jogos fúnebres, estes eram cerimônias e competições realizadas em honra a um importante rei ou herói morto (Valavanis 2004: 42). A morte do herói local Pélope (da forma como aparece nas versões míticas que vimos), "tal como aquele do guerreiro Pátroclo, teria propiciado a aition (razão) para a fundação dos Jogos Olímpicos" (Barringer 2005: 228-229).

As versões míticas dos autores antigos muito influenciaram as primeiras interpretações sobre a identificação dos edifícios mais antigos encontrados em Olímpia, como é o caso do Pelópion ${ }^{2}$, situado no setor centro-setentrional do santuário. O culto a Pélope foi considerado, por muito tempo, a primeira atividade religiosa de Olímpia, remontando ao século XI a.C., mas hoje, a época para a construção do edifício é situada no século VII a.C., o que mudou totalmente a história do culto e das edificações do santuário de Olímpia, como veremos adiante. Recentes pesquisas tendem a subestimar o papel do culto heroico na fundação dos Jogos e indicam que o culto de Pélope não foi introduzido antes de 600 a.C. (Valavanis 2004: 49).

\section{O debate atual}

A historiografia atual sobre Olímpia é menos dependente das fontes literárias e

2 Acerca do debate da cronologia do edifício, ver Jacquemin (2001: 186). mais influenciada pelas descobertas recentes da pesquisa arqueológica no local, em muito baseada na reinterpretação das antigas escavações alemãs, e pelos estudos epigráficos que têm lançado luz sobre a organização do santuário a partir da época arcaica.

\section{O espaço agonístico e o espaço de culto na época} arcaica

À época do início das competições atléticas em Olímpia - tal como hoje se aceita -, no início do século VII a.C., ocorreu um importante rearranjo arquitetônico e espacial no santuário (Fig. 1): o recinto de Pélope foi erigido sobre as ruínas do assentamento da Idade do Bronze, um espaço especial para o estádio foi organizado a leste dessa estrutura (Zolotnikova 2013: 92). De acordo com Julia Taita (2007: 107), “a instalação da pista de corrida, no primeiro quartel do século VII a.C., atesta o início dos Jogos nessa época". No início do século VI a.C., ao redor de 600 a.C., o primeiro templo dórico períptero (tradicionalmente atribuído à Hera) foi construído em Olímpia (Zolotnikova 2013: 92). Foi nessa época, no início do século VI a.C., após a reestruturação completa do santuário, que o altar de Zeus foi deslocado a leste, provavelmente para o lugar o qual viu Pausânias (Duplouy 2012: 107). O deslocamento do altar, ao redor de 600 a.C., foi parte de mudanças significativas realizadas para ampliar o espaço para a realização de sacrifícios no setor leste do santuário (Taita 2007: 107). Conforme a autora, "tratou-se de várias medidas que refletiram a exigência em reorganizar o espaço do santuário, demarcando os setores sagrados daquele agonístico e profano" (Taita 2007: 107). Uma outra opinião, contudo, interpreta o estabelecimento do primeiro estádio dentro da área sagrada, em proximidade ao altar de Zeus, pois os Jogos eram parte integrante das celebrações religiosas (Koutsoumba 2004: 99). Foi a partir dessa época, entre os séculos VII-VI a.C. que o santuário atingiu uma complexidade maior em termos espaciais, em razão do aumento do número de lugares de culto, dedicações e eventos atléticos cada vez mais frequentados por visitantes provenientes de várias áreas do mundo grego (Scott 2010: 147). 


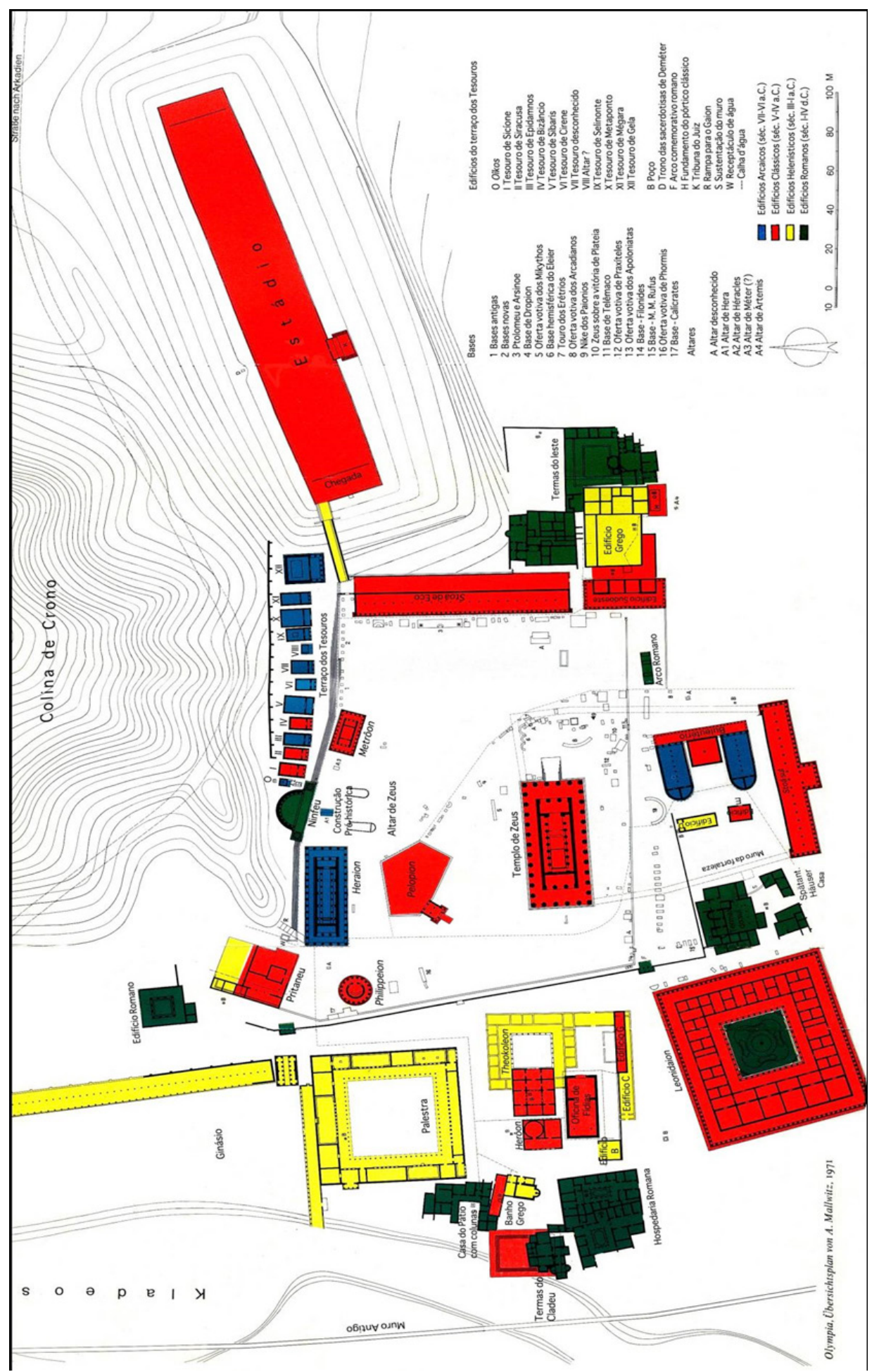

Fig. 1. Planimetria do santuário de Olímpia.

Fonte: Mallwitz (1972). 
O sentido religioso e a função política dos agōnes de Olímpia nas épocas arcaica e clássica

R. Museu Arq. Etn., 29: 60-74, 2017.

O culto de Zeus e a origem dos Jogos Olimpicos

Atualmente sugere-se que as competições atléticas em Olímpia podem ter sido formalmente instituídas como parte do antigo culto de Zeus ${ }^{3}$ no local, que remonta à Idade do Ferro. A esse respeito, muitas teorias foram propostas sobre a função do culto do deus (militar, agrária/pastoril), durante esse período, para as populações locais e de regiões vizinhas à Olímpia, com base em vários tipos de oferendas votivas encontradas no santuário, principalmente as figurinhas de bronze e de terracota.

Uma das grandes questões sobre Olímpia e o culto de Zeus durante a Idade do Ferro está na identificação de algumas das figurinhas humanas (masculinas) de terracota, aquelas mais antigas encontradas na camada de terra preta entre o Pélopion, o Heraion e a área do antigo altar de Zeus (Figs. 2 e 3). Embora haja poucos elementos que possibilitem uma classificação precisa sobre essas representações, alguns especialistas as têm considerado como as imagens mais antigas de Zeus encontradas em Olímpia e as únicas evidências que asseguram a identificação de seu culto no santuário a partir do século X a.C. (Morgan 1994: 26; Valavanis 2004: 35). De todo modo, permanece sendo aceito pelos especialistas o forte aspecto militar do culto de Zeus em Olímpia, desde a Idade do Ferro, evidenciado a partir do tipo de objetos votivos a ele dedicados no período. As figurinhas de terracota e de bronze aparecem predominantemente armadas ou usando algum tipo de equipamento defensivo, e os trípodes, adornados com figurinhas de guerreiros, evidenciam também a associação do deus às funções militares (Barringer 2010: 160; Zolotnikova 2013: 95). Embora haja evidências apenas a partir do século $\mathrm{V}$ a.C. para sua existência, assume-se que já desde o século VIII a.C. o famoso oráculo ${ }^{4}$ de Zeus em Olímpia tenha atuado em questões relativas a conflitos militares de forma parecida como nas épocas arcaica e clássica (Barringer 2015: 24).
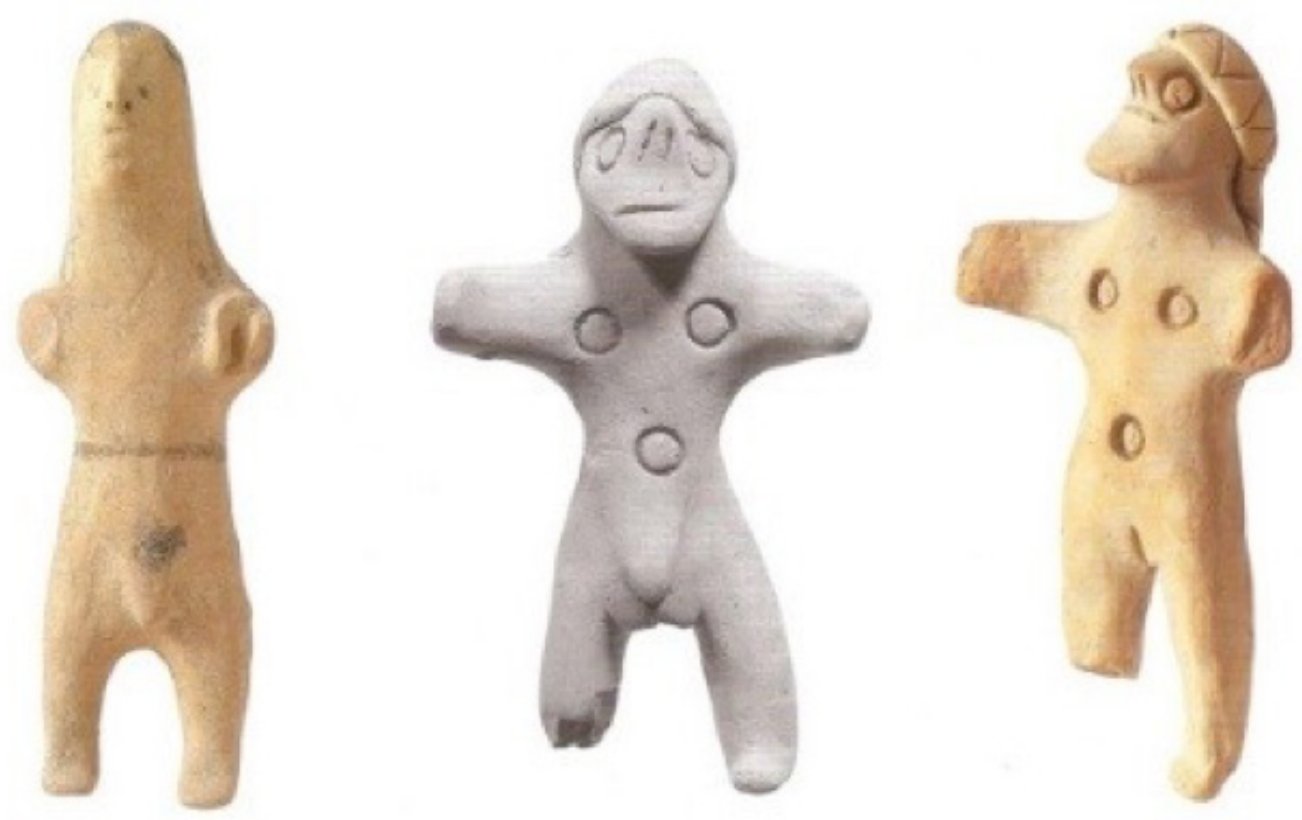

Fig. 2. Terracotas de figurinhas protogeométricas masculinas.

Fonte: Heilmeyer et al. (2012: 115, fig. 3).

3 Sobre o estado da arte da origem do culto de Zeus em Olimpia, ver Laky (2016).
4 Sobre a discussão completa da função do oráculo de Zeus Olímpio em época clássica, vide Laky (2013: 43-44). 


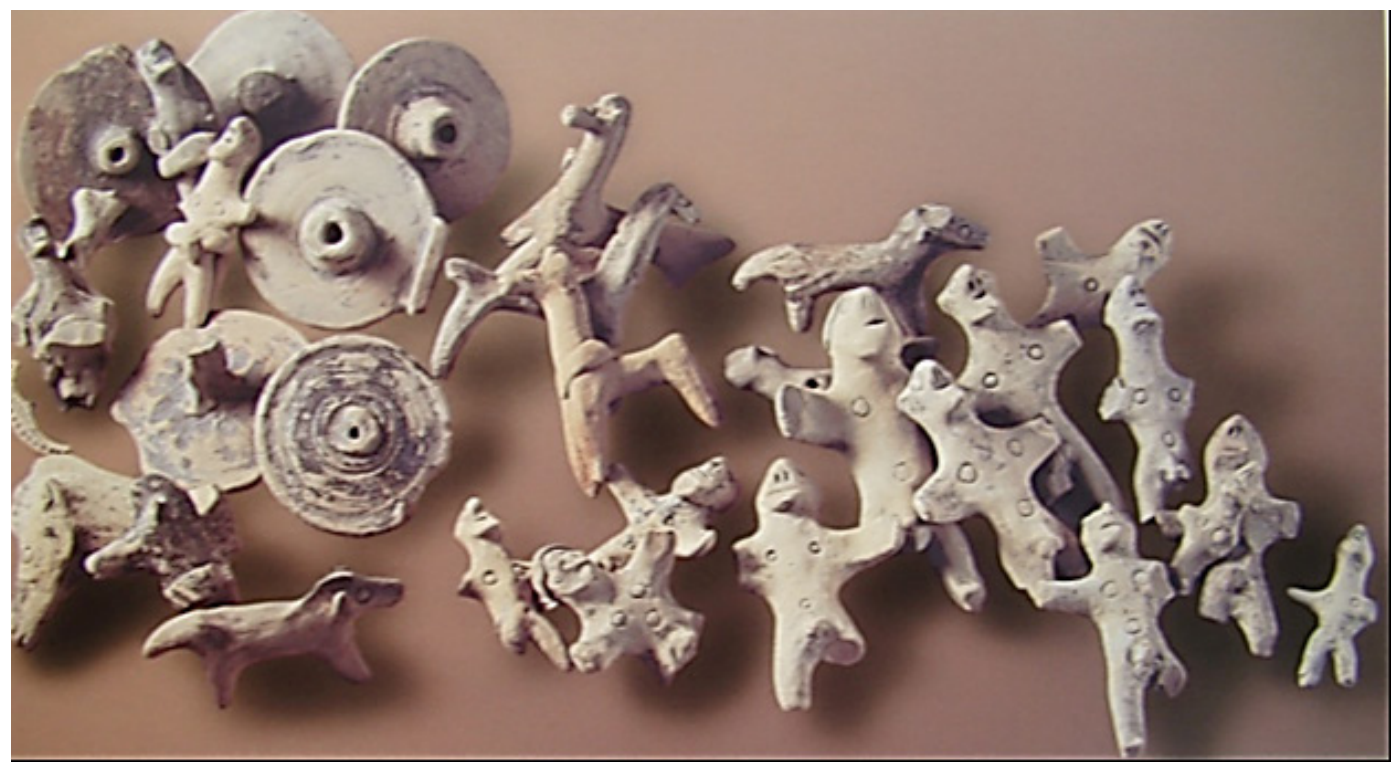

Fig. 3. Figurinhas geométricas votivas de terracota (XI-X a.C.). Fonte: Novo Museu de Olímpia (Valavanis 2004: 35, fig. 25)

Outra perspectiva, contudo, prefere relacionar o culto de Zeus em Olímpia, durante a sua fase mais antiga, aos aspectos agrários e pastoris. De acordo com Taita (2007: 89), "a tipologia das oferendas recuperadas em Olímpia (principalmente as de figurinhas de animais), pertencentes aos séculos X e IX a.C., demonstram o caráter eminente pastoril do culto no local nesse período" ${ }^{5}$ (Fig. 3). A seu ver,

o quadro histórico, social e econômico do culto em Olímpia induz a admitir que a divindade venerada desde a segunda metade do século IX a.C. teve uma conotação eminentemente atmosférica e foi procurada para garantir a fertilidade da terra e a fecundidade dos rebanhos. (Taita 2007: 95).

5 Na perspectiva de Taita, o caráter fragmentário de tais objetos votivos não oferece elementos precisos para atribuilos à tipologia de um Zeus guerreiro, mas apenas como imagens dos próprios devotos em vestes armadas (Taita 2007: 95, nota 42).
Em sua perspectiva, o oráculo de Zeus nessa época teria servido na realidade "às consultas relativas aos interesses das populações para as quais a criação de animais representava a principal fonte econômica e de prestígio social" (Taita 2007: 91, 95).

Uma terceira interpretação, sobre a fase mais antiga do culto de Zeus em Olímpia, foi recentemente proposta por Olga Zolotnikova. Em linhas gerais, segundo essa estudiosa, todas essas características apontadas (militar, agrária e pastoril) relacionam-se, no fundo, ao culto em Olímpia de uma divindade indo-europeia relacionada ao céu claro. $\mathrm{Na}$ ausência de evidências arquitetônicas seguras, é muito provável que o culto a Zeus no santuário, por muito tempo, ocorreu a céu aberto, uma característica que corresponde ao conceito de Zeus como o deus celeste, do céu claro. Os tipos das figurinhas masculinas de terracota têm fortes conotações ligadas à sexualidade masculina, ao poder masculino relacionado à fertilidade, o que indica, para essa autora, o culto de um Zeus maduro, de uma figura paterna, outro elemento do culto indo-europeu de uma divindade relacionada 
ao céu claro (Zolotnikova 2013: 97). De todo modo, aceita-se que, a partir do início da época arcaica, o aspecto militar de Zeus se sobrepôs para sempre às demais características antigas do culto ao deus em Olímpia (por exemplo, o agrário e o pastoril) (Taita 2007: 97).

A comensalidade sagrada e a oferta de miniaturas (as figurinhas de terracota humanas e animais) entraram em declínio entre o fim do século VIII a.C. e início do século VII a.C. devido a um tipo de devoção nova em Olímpia: o prestígio do oráculo de Zeus pediu a celebração de um ritual mais solene com a realização de uma grande festa que previa competições esportivas (Taita 2007: 106). Trata-se justamente do período da instalação do primeiro estádio. As competições atléticas foram parte do processo que levou à consolidação de Zeus Olímpio como uma divindade militar em época arcaica, como demonstra a inter-relação entre atletismo e guerra na cultura grega antiga ${ }^{6}$. O estabelecimento dos Jogos nessa época atesta, então, a crescente tendência do aspecto militar de Zeus no culto em Olímpia desde a Idade do Ferro, que se afirmou como característica principal do culto local da divindade até o término das atividades religiosas no santuário. A prática de dedicar despojos de guerra (Fig. 4) a Zeus Olímpio a partir do século VII a.C., bem como sua exposição na área do estádio, foi parte desse fenômeno, assim também como dedicações de estátuas de Zeus para comemorar vitórias militares, sem falar ainda nas pequenas estatuetas de bronze de Zeus Keraunios, tipos de representações do deus com importante significado militar. Essa função militar do culto de Zeus em Olímpia culminou, durante o século V a.C., no papel do deus em mediar conflitos entre as comunidades políticas em nível local e interregional, como veremos mais adiante.

6 Tal relação em Olímpia foi brilhantemente discutida por Judith Barringer (2005). Um resumo sobre a tese dessa autora pode ser visto em Laky (2013: 301-302).

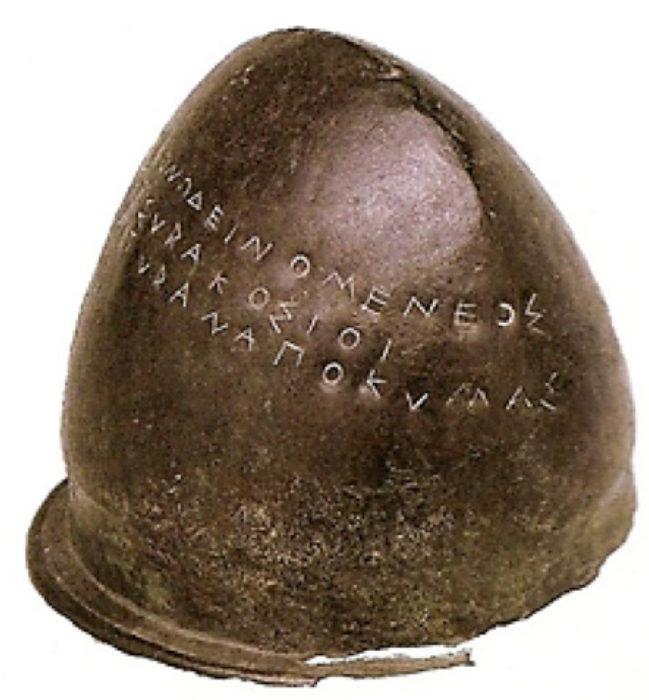

Fig. 4. Elmo etrusco dedicado por Hieron em Olímpia, c. 474 a.C.

Fonte: Novo Museu de Olímpia (Bruno 2005: 15).

\section{As funções políticas do santuário de Olímpia}

Já desde a Idade do Ferro, Olímpia desempenhou a função de um santuário subregional e inter-regional. A partir da segunda metade do século XI a.C. "o culto praticado no local funcionou como fator vinculante à unidade dos diversos grupos que gravitavam na bacia do rio Alfeu" (Taita 2007: 86). Entre os séculos IX-VIII a.C., "os objetos votivos evidenciam que o santuário havia alcançado notoriedade além desse rio", como indicam a dedicação de trípodes monumentais por visitantes da Messênia e da Arcádia e a presença, no santuário, de artesãos provenientes da Arcádia, Messênia, e de Argos, conforme estudo de tipologia e de proveniência dos objetos votivos dedicados no local nessa época (Morgan 1994: 89-90; Taita 2007: 102). Assim, é possível afirmar que a função inter-regional do santuário de Olímpia se consolidou entre os séculos IX-VIII a.C., quando o local passou a ser frequentado não apenas pelas populações do noroeste do Peloponeso, região a qual pertenceu, mas por aquelas provenientes do 
sul e nordeste dessa grande área? Embora a função sub-regional tenha se mantido nos períodos posteriores, a tendência inter-regional do santuário de Olímpia passou a se ampliar cada vez mais a partir do século VII a.C. com a instituição e expansão das competições atléticas, da prática de despojos de guerra a Zeus Olímpio, e com a participação de membros de comunidades políticas do Ocidente grego e de outras áreas da Grécia Balcânica (Laky 2013: 46). É interessante destacar sobre os despojos ${ }^{8}$ de guerra que "nenhum destes foram dedicados por Élis ou por comunidades da área do Alfeu" - tratou-se, portanto, de um tipo de oferenda tipicamente inter-regional e pan-helênica, dedicado por indivíduos de comunidades de várias partes do mundo grego.

Um traço característico de santuários extraurbanos, como Olímpia, foi a participação das elites das comunidades políticas emergentes, ainda durante a Idade do Ferro, e das cidades gregas, a partir da época arcaica. A localização extraurbana do santuário, a certa distância das maiores comunidades participantes, já na fase inicial do culto, foi um reflexo da função política e social de Olímpia como um lugar de encontro neutro às aristocracias locais das comunidades emergentes (Morgan

7 É provável ainda que a função inter-regional de Olímpia tenha se iniciado no início da Idade do Ferro, quando se originou a relação do santuário com Argos, pólis localizada no lado nordeste do Peloponeso (Morgan 1994: 89).

8 A dedicação e exposição de tropaia (despojos de guerra) parecem ter sido práticas comuns entre os espectadores e participantes dos Jogos. Milhares e diferentes tipos de armamentos defensivos, datados entre o início do século VII e o final do século V a.C., com inscrição dedicatória a Zeus Olímpio - escudos, elmos, perneiras, pontas de lanças, braçadeiras, espadas, adagas e couraças em fragmentos ou em objetos inteiros - foram e ainda são encontrados em Olímpia, principalmente no setor leste do santuário, na área do estádio (Barringer 2010: 167). De acordo com Barringer (2010: 167), "traços de buracos nos blocos do muro sul do estádio I sugerem que os tropaia eram ali expostos, pendurados em estacas de madeira - justamente no local da corrida de cavalos de maior audiência”. A prática "continuou a existir no estádio II e há evidências de que os despojos eram expostos em outras áreas do Altis" (Barringer 2010: 167). De acordo com Michael Scott (2010: 169), “a memorialização de conflitos militares através da dedicação de despojos de guerra era uma característica regular do santuário desde ao menos o século VIII a.C.”.
1993: 26; 1994: 191). Tais santuários nasceram essencialmente por duas razões: "forneceram espaços para o consumo conspícuo dos aristocratas, via atletismo e oferendas votivas, e ajudaram a resolver conflitos internos em Estados emergentes" (Neer 2007: 226). De fato, a dedicação de trípodes monumentais de bronze, que aparece pela primeira vez no século IX a.C. em Olímpia,

atesta a participação de membros de aristocracias locais que fizeram parte de um circuito de ostentação de riqueza (e possivelmente também de proeza atlética) pelo qual os aristocratas podem ter mantido seu status pessoal dentro de suas comunidades individuais. (Morgan 1993: 26; 1994: 191).

Richard Neer (2007: 228) explica que o investimento em ostentação e em comportamento de autoengrandecimento, em um culto inter-regional, poderia ser uma maneira de solidarizar-se com membros da aristocracia de outras póleis ao mesmo tempo em que esses santuários foram espaços para disputas políticas e para competições entre aristocracias locais.

\section{A atividade do Estado em Olímpia}

Data-se de fins do século VII a.C. o início da atividade do Estado em Olímpia, como indica a construção do primeiro templo períptero, dos primeiros tesouros a partir do século VI a.C. (edifícios dedicados pelas cidades gregas para salvaguardar as oferendas mais preciosas dedicadas a Zeus), localizados no sopé da colina de Cronos, e do buleutério (entre 550-500 a.C.), no setor sul do santuário (Morgan 1994: 223). A atividade do Estado tanto se refere à formalização da participação das cidades em Olímpia quanto pressupõe a existência de uma autoridade na organização e administração do santuário, como foi o caso de Élis. A participação exclusiva de Élis no desenvolvimento das funções cultuais, sem algum tipo de envolvimento de outras 
comunidades da área do Alfeu e do distrito de Pisa, é confirmada por evidências arqueológicas ao redor de 570 a.C. (Taita 2007: 141). A documentação disponível não permite precisar se se tratou de "um fato completamente novo com respeito aos períodos anteriores; se durante os séculos VIII e VII a.C. os eleios já estivessem de algum modo envolvidos no controle político do santuário de Olímpia" (Taita 2007: 141).

\section{A prostasia de Élis}

De acordo com Taita (2007: 141), que realizou um estudo crítico sobre as fontes literárias à luz da documentação epigráfica disponível para os séculos VI e V a.C.,

é irrefutável que a cidade de Élis, desde c. 570 a.C., tenha substituído o distrito de Pisa no controle da prostasia de Olímpia, dirigindo a organização das atividades sagradas e agonísticas - a documentação existente não permite afirmar se os eleios estavam de algum modo no controle de Olímpia nos séculos anteriores, apesar de isso não ser improvável.

Já James Roy (2013: 107) situa o início da administração de Élis duas décadas depois, em c. 550 a.C.

Ainda conforme Taita (2007: 36),

com certa coerência sabe-se da derrota dos pisates entre 588-572 a.C., a qual teria assinalado a passagem definitiva da prostasia para os eleios. Estes, do segundo quartel do século VI a.C. até ao redor do final do século IV d.C. - com uma única interrupção da não-Olimpíada pisatearcádia em c. 364 a.C. - detiveram a administração do santuário.

A prostasia de Élis sobre Olímpia tornouse possivel, a partir do primeiro quartel do século VI a.C., graças ao controle conquistado do corredor territorial no qual gravitavam as comunidades pisates (Taita 2007: 57 e 79). Para Taita (2007: 114), é pouco provável que apenas os eleios tenham organizado cotidianamente as cerimônias a partir do segundo quartel do século VI a.C. [...] A dedicação de votivos feitas pelas comunidades da região leva a pensar que o Estado eleio pudesse ter recorrido ao auxílio de funcionários provenientes dos assentamentos subordinados.

A participação dessas comunidades teria cessado no último quartel do século V a.C. (Taita 2007: 142). Para Roy, contudo, as inscrições, nos objetos votivos, testemunham a participação das comunidades da região no culto em Olímpia, mas não são evidências de que essas tinham parte na administração do santuário (Roy 2013: 111).

\section{Olimpia e a identidade política de Élis}

Desde ao menos a metade do século VI a.C., quando provavelmente iniciou seu controle sobre Olímpia, Élis parece ter localizado sua administração parcialmente na cidade e parcialmente no santuário, como indica o buleutério de Olímpia, datado inicialmente dessa época (Nielsen 2007: 47-48 e 50). Como bem coloca Roy, "Olímpia foi de longe o maior e mais importante santuário no território eleio, e estes, por sua vez, celebraram constantemente por lá ritos de vários cultos" (Roy 2013: 108). Os eleios utilizaram Olímpia para a administração não apenas do santuário, mas também de sua própria pólis (Roy 2013: 108). Nesse sentido, "o uso de Olímpia para propósitos políticos dos eleios caracterizam Élis como uma pólis bicêntrica" (Roy 2002: 262). Élis expunha documentos públicos em Olímpia $\mathrm{e}$, para isso, escolheu uma forma de língua que diferenciava os textos eleios de outros escritos em dialetos gregos ocidentais (Roy 2013: 108109). De acordo com T.H. Nielsen, não apenas inscrições públicas foram exibidas em Olímpia com também na própria cidade de Élis, mas edifícios públicos foram construídos em ambos os lugares (Nielsen 2007: 48). Os hellanodíkes (árbitros dos Jogos) tinham seus alojamentos na cidade de Élis e no santuário de Olímpia, assim 
como existia um buleutério em cada local (Roy 2013: 108). "Não se sabe, ao certo, se o mesmo conselho eleio se reunia em ambos os edifícios, mas, de todo modo, mesmo que tenha havido um conselho olímpico à parte, seus membros eram de Élis" (Roy 2013: 108). Para Nielsen (2007: 52),

devemos assumir que os dois conselhos (o eleio e o olímpico) foram de fato o mesmo - quando este se reunia em Élis era uma bulé comum de uma pólis e quando era transferido para Olímpia, durante as celebrações dos Jogos, era denominado de conselho olímpico, onde se podia apelar, por exemplo, contra as decisões dos hellanodikes.

Já o pritaneu, na sua fase inicial datado do início do século $\mathrm{V}$ a.C., oferece um caso à parte, pois "parece que este edifício não existiu na pólis de Élis, mas somente em Olímpia” (Roy 2013: 108). Como explica Nielsen, o edifício de Olímpia deve ter funcionado como o pritaneu de Élis e o significado de sua localização no santuário é clara - em seu centro religioso, "os eleios escolheram construir o edifício que significava a vida de uma pólis. [...] E mesmo se tenha existido um pritaneu em Élis, seu significado simbólico tornar-se-ia maior e teria servido para ligar, intimamente, cidade e santuário" (Nielsen 2007: 53).

A localização desses edifícios políades em Olímpia, bem como a exposição de decretos, foram demonstrações visíveis de afirmação do poder de Élis sobre Olímpia para uma audiência maior. $\mathrm{O}$ complexo de edifícios e o posicionamento de magistrados dessa pólis no santuário teriam servido como "uma advertência, a todos os visitantes, das relações especiais de Élis com Olímpia" (Nielsen 2007: 52). A procissão que ligava Élis e o santuário, um dos prelúdios do festival, também tem sido interpretada dessa maneira (Nielsen 2007: 46). Para Nielsen (2007: 47),

essa procissão extremamente longa teria servido como uma demonstração periódica conveniente do domínio de Élis sobre Olímpia, servindo como um sinal de supremacia, particularmente em tempos de ameaça da perda do controle dessa pólis sobre o santuário.

Como bem concluiu esse autor, Olímpia foi um componente vital da identidade local da pólis de Élis e os eleios demonstraram isso de várias maneiras: tornando-a o segundo centro da administração de sua pólis, na longa e incomum procissão da cidade ao santuário, no uso da força militar no Altis em 364 a.C. contra os arcádios e, finalmente, na escolha dos temas para os tipos monetários de sua cunhagem (Nielsen 2007: 53). "Os eleios, assim, fizeram Olímpia muito eleia" (Roy 2013: 108). "O santuário foi parte central dessa pólis e seu caráter eleio era muito claro - o controle de Olímpia foi crucial para a identidade na qual Élis se apresentou ao mundo grego" (Roy 2013: 109).

\section{Os Jogos Olimpicos e a ideologia das elites das póleis}

Durante o século VI a.C., quando Olímpia atingiu seu primeiro grande ápice como santuário inter-regional, mudanças importantes ocorreram em relação à participação das elites aristocráticas, e à afiliação às suas cidades de origem, como também à atividade do Estado no culto e o papel do santuário na formação da identidade grega no período - todos fenômenos interligados, em certo nível. Em primeiro lugar, tratou-se do período do

protagonismo da individualidade aristocrática no campo das relações entre as póleis e das atividades externas destas em escala regional e pan-helênica. [...] O ágon pan-helênico, experiência privilegiada do estilo de vida aristocrático, havia se consolidado, nessa época, como um dos modos preferidos de afirmação do status social das elites diante de sua própria cidade e diante do mundo grego. (Giangiulio 1993: 115).

Em segundo lugar, como mostra a construção do dito Heraion e dos primeiros tesouros 9 ,

9 Trata-se dos tesouros de Síbaris, Metaponto, Gela, Sicione, Epidamnos, Selinonte, Cirene e Mégara - todos são obras do século VI a.C. (Hall 2007: 271). 
entre o final do século VII e o decurso do século VI a.C. ocorreu a terceira fase de desenvolvimento de Olímpia, comum também a outros santuários inter-regionais da Grécia Balcânica: pela primeira vez o investimento em arquitetura monumental se tornou aparente. (Hall 2007: 271).

Esse fenômeno teve a ver com "o aumento do interesse do Estado em Olímpia (a formalização de sua participação) e com a institucionalização do festival olímpico e de sua incorporação dentro do círculo pan-helênico nesse período" (Morgan 1993: 26) ${ }^{10}$. Essa presença do Estado no santuário também tem relação com uma mudança na participação das elites aristocráticas em Olímpia, quando, durante o século VI a.C., estas passaram a competir nos Jogos como representantes de suas póleis (Hall 2007: 272-273). Uma evidência importante desse fenômeno foi a dedicação de edifícios, como os tesouros, ou outros tipos de monumentos, no nome das comunidades, ainda que estes tivessem sido financiados pelos mais ricos - enquanto que no século VII a.C. tal prática era realizada para os membros das elites obterem renome e glória individuais nos santuários inter-regionais (Hall 2007: 272-273). Tratou-se, nesse caso, de uma mudança observada também em outros santuários além de Olímpia.

Olímpia como espaço político: mediação de conflitos e exposição de decretos

Após essa explicação da função de Olímpia entre as elites das cidades gregas, desde o início da atividade cultual no local, resta mencionar o papel mais importante desempenhado pelo santuário em relação às comunidades políticas a partir do século $\mathrm{V}$ a.C.: a mediação e arbitragem de conflitos locais e inter-regionais. Como bem coloca Taita, "a autoridade de Zeus Olímpio representou a

10 Já a partir do século VI a.C. "Olímpia fazia parte de um circuito de jogos stefaníticos estabelecidos nos principais santuários inter-regionais além de Olímpia, como de Apolo em Delfos, de Poseidon em Ístmia e de Zeus em Neméia” (Hall 2002: 154). garantia suprema que sancionava a instauração de relações pacíficas intercomunitárias e regulava eventuais controvérsias a nível local" (Taita 2007: 141-142). Em nível sub-regional, evidências epigráficas testemunham acordos entre comunidades da área do Alfeu durante o século V a.C., como o tratado de $\varphi \imath \lambda i ́ \alpha$ entre os Anaitoi e os Metápioi ${ }^{11}$ (Taita 2007: 45-46). De acordo com Barringer, no início do século V a.C., "a implementação da arbitragem em Olímpia foi uma consequência direta das guerras pérsicas: a vitória alcançada em Plateias por meio da unidade dos gregos inspirou a implementação de uma arbitragem para evitar conflitos entre os gregos" (Barringer 2015: 30). A partir dessa época, "tratados internacionais passaram a cada vez mais a serem publicados em Olímpia para obter a sanção religiosa, no caso de Zeus Olímpio, e para assim garantir uma grande audiência, devido aos Jogos, e direitos contra violações dos termos" (Nielsen 2007: 79-81). Conforme Nielsen \& Roy (2009: 266), "ao publicarem tais tratados, as comunidades também ostentavam sua 'estatura' e afirmavam seu lugar no mundo grego". A função de asylia de Olímpia tornou o santuário um lugar igualmente propício para a realização de acordos entre as cidades. Missões diplomáticas colocavam-se sob a proteção do santuário a fim de tornar difícil aos negociantes do outro lado rejeitar seus pedidos. Tucídides (III. XIV. 1-2 - XV) nos fornece o principal testemunho a esse respeito ao narrar o discurso dos mitilênios em Olímpia em 428 a.C. no contexto da guerra do Peloponeso. Após terem deixado a liga ateniense, os mitilênios requereram a adesão à liga peloponésia em uma reunião no santuário: "em vista do fato de que estavam reunidos em Olímpia, tornavam-se automaticamente suplicantes de Zeus o que impedia a rejeição de seu pedido de adesão" (Sinn 2000: 157; 158 , nota 8 ).

11 Essas inscrições, encontradas em Olímpia, sobre acordos, atos públicos, ao lado de diferentes tipos de oferenda, todos datados do século V a.C., são testemunhos também da existência de várias comunidades independentes à Élis na área da bacia do Alfeu nesse período. A esse respeito, ver Taita (2007: 41-48). 
De acordo com interpretações mais recentes, esse papel de Olímpia e de Zeus Olímpio, na mediação e arbitragem de conflitos, alcançou um momento importante após a metade do século $\mathrm{V}$ a.C., no contexto da guerra do Peloponeso. O declínio da dedicação de despojos de guerra, nessa época, teria sido um reflexo de uma proibição para evitar ofensas entre as cidades participantes nos Jogos e no culto. No entanto, outros tipos de dedicações, relativas a certas comemorações militares, continuaram a ocorrer em Olímpia. Tal fato é explicado por James Roy em um recente artigo como negociações entre a comunidade ofertante e Élis ou, ainda, como pressões que às vezes a pólis administradora do santuário precisava ceder ao aceitar tal tipo de dedicação (Roy 2013: 116).

O papel do santuário na exposição de decretos, leis e tratados referentes às regras do santuário, envolvendo ou não outras comunidades, continuou como uma prática no local até o período romano (Barringer 2015: 30).

\section{Considerações finais: os Jogos Olímpicos e a afirmação de identidades políticas, étnicas e regionais em época arcaica e clássica}

Em síntese, Olímpia foi o "centro mais importante de interação e exibição para as póleis desde a época arcaica" (Nielsen \& Roy 2009: 266). Essa é uma visão de Thomas Heine Nielsen, do Copenhagen Polis Centre, que discutiu a importância e contribuição do santuário de Olímpia em época clássica, tido como a principal arena na qual os dois níveis mais característicos de identidade grega (a identidade helênica global compartilhada em oposição aos bárbaros e a identidade individual da pólis de cada comunidade) foram negociados, desenvolvidos e mantidos (Nielsen 2007: 10). Valendo-se do conceito de interação no mundo grego, o estudioso examina o papel desempenhado pelo santuário no período como o foco de interação helênica e como o ponto de encontro para a expressão da diferença entre gregos e bárbaros (Nielsen 2007: 11). De acordo com Nielsen, Olímpia foi uma instituição de importância crucial na cultura da cidade grega, pois ajudou a criar e a manter um grau de similaridade na enorme diversidade produzida pela existência de mais de mil póleis altamente individualizadas e radicalmente autodiferenciadas. Foi também uma instituição que contribuiu para a formação e manutenção da diversidade dentro da similaridade que ela própria promoveu. Em outras palavras, através do processo de interação, em Olímpia foram confirmadas e continuamente reconfirmadas a identidade helênica global a qual todas as póleis gregas compartilharam e as identidades locais das póleis individualizadas, tidas como únicas, cada uma em sua própria maneira (Nielsen 2007: 99).

A similaridade foi produzida pelo santuário de Olímpia por proporcionar um dos meios pelos quais os gregos continuamente redesenharam o limite entre eles mesmos e os bárbaros, assim criando e reconfirmando a identidade grega (Nielsen 2007: 17; 99). Conforme Nielsen, três pontos são importantes nesse aspecto. Primeiro, na visão helênica de época clássica o atletismo foi um fenômeno grego único e característico, e a importância de Olímpia nesse aspecto reside no simples fato de que era o local do mais proeminente de todos os espaços gregos de competições. $\mathrm{O}$ segundo ponto, segundo o autor, é o de que os Jogos Olímpicos permaneceram etnicamente exclusivos, uma vez que apenas os gregos eram admitidos a participar. Essa exclusividade étnica desenvolveu-se como uma consequência de (ou foi intensificada por) conflitos dos gregos com os persas, e a ocasião que induziu a formulação explícita do princípio de exclusividade pode ter sido as discussões causadas pela participação de Alexandre I da Macedônia (498-454 a.C.), um aliado persa cujas credenciais gregas poderiam ser (e foram) contestadas ${ }^{12}$. A esse respeito é sintomático o início do uso denominação hellanodikes ("os juízes dos helenos") no

12 Enquanto não há razões para duvidar que os Jogos Olímpicos tenham sido de fato um fenômeno puramente helênico no período arcaico, devemos, contudo, notar que não há informação sobre algum bárbaro que desejou competir em Olímpia antes de Alexandre I, cuja identidade étnica poderia ser reconhecida e negada como helênica (Nielsen 2007: 19-20). 
começo do século V a.C.13 Até o século VI a.C., os árbitros ou juízes das competições eram nomeados de diaitetés (Nielsen 2007: 20-21). $\mathrm{O}$ terceiro ponto refere-se estritamente ao atletismo, responsável por tornar visivelmente nítida a diferença entre gregos e bárbaros: os gregos competiam nus, ao passo que os bárbaros, que praticavam o atletismo, não competiam desse modo (Nielsen 2007: 99). Nesse sentido, a novidade do estudo de Nielsen está em considerar o atletismo praticado nu em Olímpia como um fator importante no desenho do limite entre o mundo grego e o mundo bárbaro, visto que o santuário foi o principal espaço dessa prática estritamente grega (Nielsen 2007: 100).

A diversidade interna, por outro lado, foi também criada e mantida em Olímpia, onde as inumeráveis póleis enfatizaram sua individualidade pela competição através de suas dedicações e de seus atletas. Dedicações comunais aumentavam o prestígio da comunidade oferecedora (Nielsen 2007: 74). Atletas competiam em Olímpia não apenas como indivíduos, mas como representantes de suas póleis de origem ${ }^{14}$ (Nielsen 2007: 86). Praticamente todas as póleis exploraram Olímpia como um fórum no qual avivaram e enfatizaram suas identidades individuais. Considerando apenas as evidências discutidas em seu estudo, Nielsen contabilizou que ao menos 102 póleis de todos os cantos do mundo grego tiveram relações com o santuário em época clássica. Esse número é significativo em vista do estado fragmentário das evidências: trata-se de cerca de $10 \%$ de todas as póleis incluídas no An inventory of archaic and classical poleis (Nielsen 2007: 100-101).

As competições em Olímpia foram concebidas não meramente como Jogos entre atletas individuais, mas como competições entre póleis que exploraram avidamente a oportunidade para aumentar seu prestígio. Em outras palavras, Olímpia gerou uma interação extremamente intensa e extensiva entre as póleis helênicas, que foram autorizadas a enfatizar a sua individualidade. Assim, Olímpia foi um palco bem adaptado para essa interação, uma vez que era, ao menos durante os festivais, o santuário mais visitado em todo o mundo grego, onde se reuniu uma grande quantidade de delegações, atletas e espectadores. Em síntese, as multidões em Olímpia fizeram parte de um dos processos sociopolíticos pelos quais os gregos demonstraram que eles não eram apenas gregos, mas também mantineus, cireneus, lepreatas e ainda myaneus e assim por diante (Nielsen 2007: 101).

LAKY, L.A. Religious meaning and political role of the Olympic agones in the archaic and classical periods. R. Museu Arq. Etn., 29: 60-74, 2017.

Abstract: This article presents a brief summary on the conditions of art about the sanctuary of Olympia, considered the religious and political center of the Greek world during the Archaic and Classical periods. The Olympic games are presented as part of a singularly Greek religious and political phenomenon in both periods. Within this perspective, the role of the Olympic games and the cult of Zeus in the mobilization of political elite groups and as affirmation of political, ethnic and regional identities is discussed in this paper.

Keywords: Olympia; Olympic Games; Identities; Zeus; Sanctuaries.

13 A evidência literária mais antiga do termo hellanodikes está em Píndaro (Ol. 3. 12), e nas evidências epigráficas ( $($ v O 2.5) o termo aparece em inscrições datadas de c. 475-450 a.C. (Nielsen 2007: 20).

14 A identificação de um atleta com a sua pólis era visível de várias maneiras em Olímpia. O campeão olímpico tinha o direito de comemorar o seu feito erigindo um monumento no Altis. O nome da pólis era incluído na proclamação da vitória e nas inscrições das esculturas comemorativas. Outra forma em que o nome da pólis de origem de um campeão poderia ser proclamado era através do uso do étnico da cidade na base da estátua dedicada pela vitória (Nielsen 2007: 88-89). 


\section{Referências bibliográficas}

Barringer, J. 2005. The temple of Zeus at Olympia, heroes, and athletes. Hesperia 74: 211-241.

Barringer, J. 2010. Zeus in Olympia. In: Erskine, A.; Bremmer, J.N. (Eds.). The gods of ancient Greece: identities and transformations. Edinburgh University, Edinburgh, 155-177.

Barringer, J. 2015. The changing image of Zeus at Olympia. AA 1: 19-37.

Bruno, G. 2005. Aristocrazia, tirannide e democrazia. In: Minà, P. (Org.). Urbanistica e architettura nella Sicilia greca. Assessorato dei Beni Culturali Ambientali e della Pubblica Istruzione, Palermo, 15-20.

Duplouy, A. 2012. Culti e cultura nella Grecia di età geométrica (1000-750 a.C.). In: Atti del Cinquantesimo Convegno di Studi sulla Magna Grecia, 2010, Tarento, 103-132.

Estrabão. 1960. The geography (Jone, H.C., trad.). Harvard University Press, Cambridge; Londres.

Giangiulio, M. 1993. Le Città di Magna Grecia e Olimpia in età arcaica: aspetti della documentazione e della problematica storica. In: Mastrocinque, A. (Ed.). I grandi santuari della Grecia e l'Occidente. Labirinti. Trento, Università degli Studi di Trento, Trento, 93-118. v. 3.

Hall, J.M. 2002. Hellenicity: between ethnicity and culture. Chicago University, Chicago.

Hall, J.M. 2007. A history of archaic Greek world: ca. 1200-479 BCE. Blackwell, Malden.

Heilmeyer, W.D. et al. 2012. Mythos Olympia: Kult und Spiele. Prestel, München.

Homero. 2004. Ilíada (Nunes, C.A., trad.). Ediouro, Rio de Janeiro.

Jacquemin, A. 2001. Pausanias, témoin de la religion grecque dans le sanctuaire d'Olympie. In: Pasquier, A. (Ed.). Olympie: cycle de huit conférences organisé au Musée du Louvre par le Service culturel du 18 janvier au 15 mars 1999. Musée du Louvre, Paris, 181-213.

Koutsoumba, D. 2004. Olympia: archaeological guides. Explorer, Atenas.

Laky, L.A. 2013. Olímpia e os Olimpiéia: a origem e difusão do culto de Zeus Olímpio na Grécia dos séculos VI e V a.C. Revista do Museu de Arqueologia e Etnologia suplemento 16: 1-336.

Laky, L.A. 2016. A apropriação e consolidação do culto de Zeus pela cidade grega: moedas e santuários, política e identidade em época arcaica e clássica. Tese de doutorado. Universidade de São Paulo, São Paulo.

Mallwitz, A. 1972. Olympia und seine Bauten. Prestel, München.

Morgan, C. 1993. The origins of pan-hellenism. In: Marinatos, N.; Hägg, R. (Eds.). Greek sanctuaries: new approaches. Routledge, London, 18-44.

Morgan, C. 1994. Athletes and oracles: the transformation of Olympia and Delphi in the eighth century B.C. Cambridge University, Cambridge.

Neer, R.T. 2007. Delphi, Olympia, and the art of politics. In: Shapiro, H.A. (Ed.). The Cambridge companion to archaic Greece. Cambridge University, Cambridge, 225-264.

Nielsen, T.H. 2007. Olympia and the classical Hellenic city-state culture. HfM 96: 1-139.

Nielsen, T.H.; Roy, J. 2009. The Peloponnese. In: Raaflaub, K.A.; Wees, H. (Eds.). A companion to archaic Greece. Willey-Blackwell, Oxford, 255-272.

Pausânias. 1954. Description of Greece (Jones, W.H.S.; Ormerod, H.A., trad.). William Heinemnann, Londres; Harvard University Press, Cambridge. 
O sentido religioso e a função política dos agōnes de Olímpia nas épocas arcaica e clássica

R. Museu Arq. Etn., 29: 60-74, 2017.

Píndaro. 1997. Nemean odes. Isthmian odes. Fragments (Race, W.H., trad.). William Heinemnann, Londres; Harvard University Press, Cambridge.

Roy, J. 2002. The synoikism of Elis. In: Nielsen, T.H. (Ed.). Even more studies in the ancient Greek polis. Franz Steiner, Stuttgart, 249-264.

Roy, J. 2013. Olympia, identity and integration: Elis, Eleia, and Hellas. In: Funke, P.; Haake, M. (Eds.). Greek Federal States and their sanctuaries: identity and integration. Franz Steiner, Stuttgart, 107-122.

Sarian, H. 1997. Culto heróico, cerimônias fúnebres e a origem dos Jogos Olímpicos. Clássica 9 (9-10): 45-72.

Scott, M. 2010. Delphi and Olympia: the spatial politics of panhellenism in the archaic and classical periods. Cambridge University, Cambridge.
Sículo, D. 1963. Library. (Oldfather, C.H., trad.). Harvard University Press, Cambridge.

Sinn, U. 2000. Greek sanctuaries as places of refuge. In: Buxton, R. (Ed.). Oxford readings in Greek religion. Oxford University, Oxford, 70-87.

Taita, J. 2007. Olimpia e il suo vicinato in epoca arcaica. Edizione Universitarie di Lettere Economia Diritto, Milano.

Valavanis, P. 2004. Games and sanctuaries in ancient Greece: Olympia, Delphi, Isthmia, Nemea, Athens. Kapon Editions, Athens.

Yalouris, N. (Org.). 2004. Os Jogos Olímpicos na Grécia antiga. Tradução direta do grego moderno e notas Luiz Alberto Machado Cabral. Odysseus, São Paulo.

Zolotnikova, O.A. 2013. Zeus in the early Greek mythology and religion: from prehistoric times to early archaic period. Archeopress, Oxford. 